\title{
A Esquistossomose Urbana e a Heterogeneidade Social e Epidemiológica da População do Município de Campinas, São Paulo, Brasil' ${ }^{1,2}$
}

\author{
Urban Schistosomiasis and Social and Epidemiological Heterogeneity in \\ Campinas, São Paulo, Brazil
}

Virgília L. C. de Lima3

\section{LIMA, V. L C. Urban Schistosomiasis and Social and Epidentiological Heterogeneity in Campinas, São Paulo, Brazil. Cad. Saúde Públ., Rio de Janeiro, 11 (1): 45-56, Jan/Mar, 1995.}

This study deals with the relationship between schistosomiasis and urbanization, particularly the urbanization process experienced by cities in dependent capitalist countries, with large groups of people in precarious living conditions. Six hundred and ten notified autochthonous cases in Campinas during the period from 1970 to 1990 are analyzed through notification files with regard to patients' socio-economic conditions.

Autochthonous cases of schistosomiasis were demonstrated as having a more heterogeneous geographical distribution within the urban area than could be inferred from previous studies that correlate the occurence of transmission with precarious sanitary conditions.

Key words: Schistosomiasis; Urbanization; Medical Geography; Social Heterogeneity

\section{INTRODUÇÃO}

A esquistossomose é uma das doenças infecciosas e parasitárias que se vêm urbanizando nas últimas décadas. O fenômeno da urbanização de enfermidades anteriormente próprias do meio rural vem preocupando as autoridades de saúde (Knudsen \& Slooff, 1992; Mott et al., 1990; Kvalsvig \& Schutte, 1986).

No estado de São Paulo, essa feição da doença é evidenciada em vários municípios po-

\footnotetext{
${ }^{I}$ Esta investigação recebeu apoio financeiro do Programa Especial de Investigação e Treinamento em Enfermidades Tropicais PNUD/Banco Mundial/ Organização Mundial da Saúde (OMS).
}

pulosos e industrializados (SES/Sucen, 1982; Alves, 1983). Entre eles, sobressai-se o município de Campinas (latitude 22540, longitude 47050), por ser sede de uma região que se constitui no terceiro pólo industrial do país. O município, com população de 860 mil habitantes, apresenta taxa de urbanização de $97,3 \%$ e tem $39,6 \%$ de sua população economicamente ativa inserida no setor secundário, $56,2 \%$ no terciário e apenas 2,5\% no primário (IBGE, 1983). Possui economia dinâmica e diversificada para os padrões do país (Prefeitura Municipal de Campinas, 1991; Seade, 1983). Com relação à esquistossomose, Campinas apresentou os primeiros casos autóctones no ano de 1960. Desde então os serviços de saúde do município vêm notificando a média de casos autóctones de 6,5 casos por 100 mil habitantes por ano. Entre os levantamentos coproscópicos existentes, realizados em escolares e em algumas localidades, encontrou-se prevalência autóctone que se situou na maioria dos casos entre 0 e $5 \% \mathrm{O}$ valor mais elevado encontrado foi de $11,6 \%$ A transmissão se dá, na maioria 
dos casos, provavelmente, por ocasião do lazer, sendo o hospedeiro intermediário encontrado na região a Biomphalaria tenagophila (SES/Sucen, 1982). Observa-se no município a ampliação da área de transmissão ao longo do tempo e deslocamento dos locais de transmissão no sentido do centro para a periferia (Lima, 1993).

Da necessidade de estudar a esquistossomose em Campinas para dar respostas em relação ao seu controle e também apontar tendências, surgiu este estudo, com o objetivo de compreender o processo de introdução e manutenção da doença ao longo do tempo no município.

Partiu-se do pressuposto de que a introdução e a distribuição da transmissão da esquistossomose no município de Campinas são determinadas pelo processo de organização do seu espaço geográfico e, mais especificamente, pelo seu processo de urbanização (Dolfuss, 1972; Moraes \& Costa, 1987). O estudo, então, orientou-se para o detalhamento das relações entre a doença e a urbanização do município. Aqui está relatado um segmento desse estudo. Trata-se da análise das condições socioeconômicas da população com esquistossomose adquirida no município no período de 1970 a 1990.

A esquistossomose é freqüentemente relacionada com precárias condições de vida (Mott et al., 1991; Doumenge, 1987). Sendo a proposta deste estudo estabelecer as relações da esquistossomose com a urbanização, caso se configurasse a doença como problema, prioritariamente, da parcela da população que se aglomera nas periferias das cidades, sobrevivendo às custas de subempregos, como serviços domésticos, biscates etc, e habitando áreas desprovidas de serviços urbanos necessários para uma qualidade de vida que se possa denominar humana (Singer, 1987), estaria se relacionando a endemia com uma característica importante da urbanização dos países do terceiro mundo.

\section{MATERIAL E MÉTODOS}

Para o estudo das condições socioeconômicas das pessoas com esquistossomose autóctone foram utilizadas as informações existentes na ficha epidemiológica de casos notificados. Além disso, foram usados dados censitários sobre renda familiar, por bairro, e informações sobre saneamento básico e localização de favelas existentes na prefeitura municipal.
Foram utilizadas as 610 fichas epidemiológicas de casos autóctones notificados até o ano de 1990, encontradas no Serviço Regional da Superintendência de Controle de Endemias (Sucen), autarquia estadual responsável pelo controle das doenças transmitidas por vetores no estado de São Paulo. Foram tabuladas as seguintes informações nelas existentes: ano da detecção do caso, ocupação, local de trabalho, coleções hídricas referidas e endereço de residência.

Utilizando-se o número de casos autóctones notificados por ano em duas regiões do município com diferentes condições socioeconômicas, separadas pela rodovia Anhanguera, foram calculados coeficientes de casos autóctones notificados (número de casos autóctones notificados na região no ano/população da região no ano x 1000) para o período de 1980 a 1990. Para esses cálculos, fez-se uso de estimativas de população para cada região existente na prefeitura municipal (Prefeitura Municipal de Campinas, 1991).

Foram mapeados, também, os valores das prevalências de casos autóctones encontrados em levantamentos coproscópicos realizados pela Sucen em algumas escolas e bairros, levando em consideração a divisão do município referida.

Os casos autóctones foram ainda agrupados de acordo com o bairro de moradia e com a divisão da prefeitura em administrações regionais. Bairros próximos geograficamente, cujos portadores de esquistossomose referiam contato com determinadas coleções hídricas, foram agrupados em "áreas".

Foram ainda mapeadas as favelas do município, as redes de água e esgoto e os bairros por nível de renda familiar, e superpostas a esses mapeamentos as "áreas" com transmissão de esquistossomose.

Para uma análise epidemiológico-social mais adequada, partiu-se para uma estratificação com critérios ocupacionais. A variável ocupação foi, então, classificada de acordo com dois modelos, o utilizado na Classificação Brasileira de Ocupações (MT, 1982) e o sugerido por Possas (1989). Resolveu-se lançar mão dos dois tipos de classificação por se acreditar que eles sejam complementares para a análise que se pretendia e que essa fosse a forma de melhor aproveitar as informações disponíveis. 
A Classificação Brasileira de Ocupações (CBO), por especificar as ocupações de acordo com o tipo de atividade executada, permite obter alguma informação quanto a sua qualificação. Para isso foi feita uma adaptação a essa classificação com a finalidade de agrupar ocupações que se poderiam considerar não-qualificadas.

Essa classificação agrupa as ocupações em 10 grandes grupos de 0 a 9 e, dentro deles, em grupos específicos. Existe um grupo específico, comum a todos os grandes grupos, que é o 99, onde são agrupados os ajudantes e auxiliares, desde que não executem atividade específica, como é o caso, por exemplo, do auxiliar de escritório. Para fins da análise deste estudo foram colocadas também nesse grupo ocupações registradas nas fichas epidemiológicas e não-existentes na classificação do $\mathrm{CBO}$, e que podem ser consideradas não-qualificadas, como "carregador de caminhão", "empacotador de supermercado", "bagageiro", "servente", "servente de pedreiro", "entregador", "office boy”, "serviços gerais". Resolveu-se incluir, também, nesse item os casos em cujas fichas havia apenas a denominação "operário", "industriário", "operador de produção", pela falta de especificação da ocupação. Foram incluídas, ainda, nesse grupo as ocupações "guardinha" e "patrulheiro-mirim", que são tarefas oferecidas a menores de idade, patrocinadas por associações do comércio e da indústria.

O modelo de Possas presta-se melhor ao entendimento das condições de vida e trabalho, relacionadas com a categoria ocupacional do indivíduo. No entanto, as poucas informações existentes nas fichas epidemiológicas dificultavam o preenchimento dos diversos itens propostos pela autora. Resolveu-se adaptar os dados ao modelo proposto, por se achar ser ele instrumento de grande ajuda na mediação necessária entre a endemia estudada e as questões sociais. Para essa adaptação foram inferidas algumas informações a partir dos dados disponíveis, expostas a seguir.

Para o preenchimento da variável "Ramo de Atividade", foram utilizados os dados existentes na ficha epidemiológica nos itens "ocupação" e "local de trabalho". No entanto, freqüentemente a informação sobre o local de trabalho registrava o endereço, nem sempre completo, e não o nome da empresa ou instituição. Nesses casos, quando se tratava de profissões próprias de algum dos ramos de atividade existentes na classificação, este era considerado (por exemplo, metalúrgico, operador de produção, operário, fresador, torneiro no ramo de indústria de transformação, balconista, vendedor no ramo de comércio de mercadorias, serviços domésticos no ramo de prestação de serviços); caso contrário, o caso era tabulado como sem informação em relação a esse item.

Foram considerados "não-ocupados" os estudantes, as mulheres que trabalham em sua própria casa, classificadas como "do lar", os menores de 16 anos em cujas fichas nada havia no item "ocupação" e que, pelo seu elevado número, justificaram a criação dessa categoria, e, por fim, os presidiários. No item "Desocupados" foram considerados os desempregados e aqueles em cuja ficha havia um sinal negativo no local da ocupação. Quanto ao item sobre a condição de empregado, empregador ou conta-própria, seguiu-se orientação semelhante à do item "Ramo de Atividade". As ocupações próprias da condição de empregado, como emprego doméstico, operário, auxiliares diversos, encarregados etc., foram assim considerados mesmo quando não havia registro da instituição empregadora. As ocupações que podem ser desenvolvidas tanto como empregado como por conta própria, e não havendo registro claro do local de trabalho, foram consideradas sem informação em relação ao item. Só foram consideradas trabalhadores por conta própria quando havia alguma referência que indicava esse tipo de inserção no mercado de trabalho, o mesmo ocorrendo com a condição de empregador.

Para algumas análises, dividiu-se o período de estudo em intervalos de cinco anos, com exceção do primeiro, que foi de 1970 a 1975 . Só a partir de 1979 é que as informações foram preservadas na sua totalidade, pois, em 1978, começou a funcionar o Sistema de Vigilância Epidemiológica do Estado. Por essa razão, algumas análises só abordaram os três últimos intervalos. $\mathrm{O}$ intervalo de 1976 a 1980, apesar de não estar completo, teve grande quantidade de notificações nos anos de 1979 e 1980, o que permite analisá-lo com os cuidados pertinentes. 


\section{RESULTADOS}

Analisando os coeficientes de casos autóctones nas duas regiões do município separadas pela rodovia Anhanguera (Tabela 1), observa-se que há muita oscilação nos valores, ao longo do tempo, não sendo possível afirmar que exista predominância de casos notificados em nenhuma das duas. Pode-se observar, no entanto, por meio da Figura 1, que o setor acima da Anhanguera apresenta valores de prevalência autóctone, nos levantamentos coproscópicos realizadas pela Sucen, mais elevados do que os do setor abaixo dessa rodovia.
As ARs com maior número de casos autóctones foram as AR 3, AR 7 e AR 90 (Figura 2).

A Figura 3 mostra a relação das áreas de transmissão do município com a localização das favelas. Nessa figura constata-se que a maior concentração de favelas está na região sudoeste do município, onde se localizam as ARs 7 e 12. Observe-se a ausência de áreas de transmissão na zona leste do município. Existe, no entanto, um aglomerado de favelas nessa região. Observa-se, ainda, o pequeno número de favelas na região norte da cidade, a qual constitui a AR 90. Há transmissão nas duas favelas nela existentes, porém observa-se

TABELA 1. Coeficiente por 1000 Habitantes de Casos Autóctones Notificados nos Dois Setores do Município de Campinas, Abaixo e Acima da Anhanguera, Campinas, 1980-1990

\begin{tabular}{lccccccccccc}
\hline \hline & \multicolumn{10}{c}{ Ano } \\
\cline { 2 - 11 } Setores & 80 & 81 & 82 & 83 & 84 & 85 & 86 & 87 & 88 & 89 & 90 \\
\hline $\begin{array}{l}\text { Abaixo } \\
\text { Anhanguera }\end{array}$ & 0,09 & 0,16 & 0,13 & 0,04 & 0,009 & 0,03 & 0,01 & 0,01 & 0,04 & 0,04 & 0,05 \\
Acima & & & & & & & & & & & \\
Anhanguera & 0,13 & 0,09 & 0,04 & 0,04 & 0,01 & 0,03 & 0,02 & 0,008 & 0,08 & 0,05 & 0,03 \\
\hline \hline
\end{tabular}

que as outras áreas aí situadas apresentam grande número de casos e prevalências de levantamentos coproscópicos relativamente elevadas, e não apresentam favelas.

Colocando os bairros com casos de esquistossomose em um mapa elaborado pela prefeitura, que relaciona os bairros da cidade por faixa de renda com base nos dados do recenseamento populacional do ano de 1980, observa-se que estes últimos compreendem bairros das três faixas de renda mais baixas. Não há suspeita de transmissão nos bairros correspondentes às duas faixas de renda restantes, que são as mais elevadas. Observa-se, também, que os bairros das áreas de transmissão com a faixa de renda mais alta das três são mais freqüentes na porção acima da Anhanguera, concentrando a porção abaixo dessa rodovia as áreas de transmissão com bairros das duas faixas de renda mais baixas.

Comparando agora as porções do município com ausência de rede de esgoto e de abasteci- mento de água com as áreas com transmissão de esquistossomose em mapas onde esses serviços foram representados, observa-se que, de maneira geral, apenas os locais de transmissão mais recente, que são também de povoamento recente e situados na periferia, tanto na região sudoeste como na região norte, têm carência desses serviços.

Ao listar os casos por ocupação, observou-se grande predominância de estudantes e de menores de 16 anos, $41,2 \%$ e $12,1 \%$ respectivamente. As demais categorias não apresentaram distribuição que merecesse maior atenção.

De acordo com a posição na ocupação, observou-se que $54,8 \%$ do casos eram de "não ocupados", categoria em que se encontram estudantes, menores de 16 anos e mulheres "do lar", e 40,5\% de ocupados. Dos ocupados, $73,0 \%$ foram classificados como empregados, $3,8 \%$ como trabalhadores por conta própria, e, para $23 \%$, não se conseguiu informação. 
FIGURA 2. Número de Casos Autóctones Notificados por Administração Regional e Intervalo, Campinas, 1970-1990

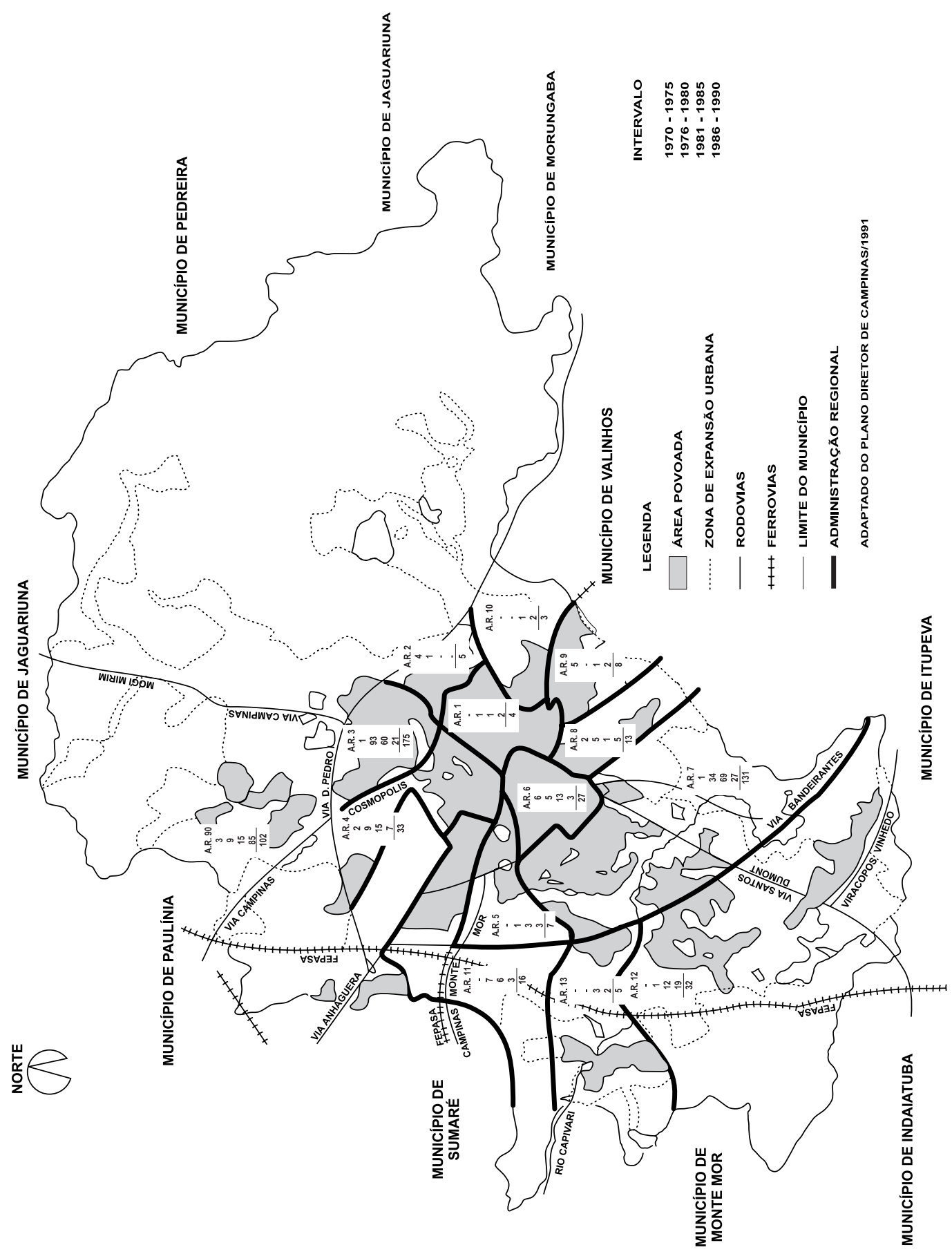


FIGURA 1. Prevalência Autóctone dos Levantamentos Coproscópicos Realizados, Campinas , 1970-1990

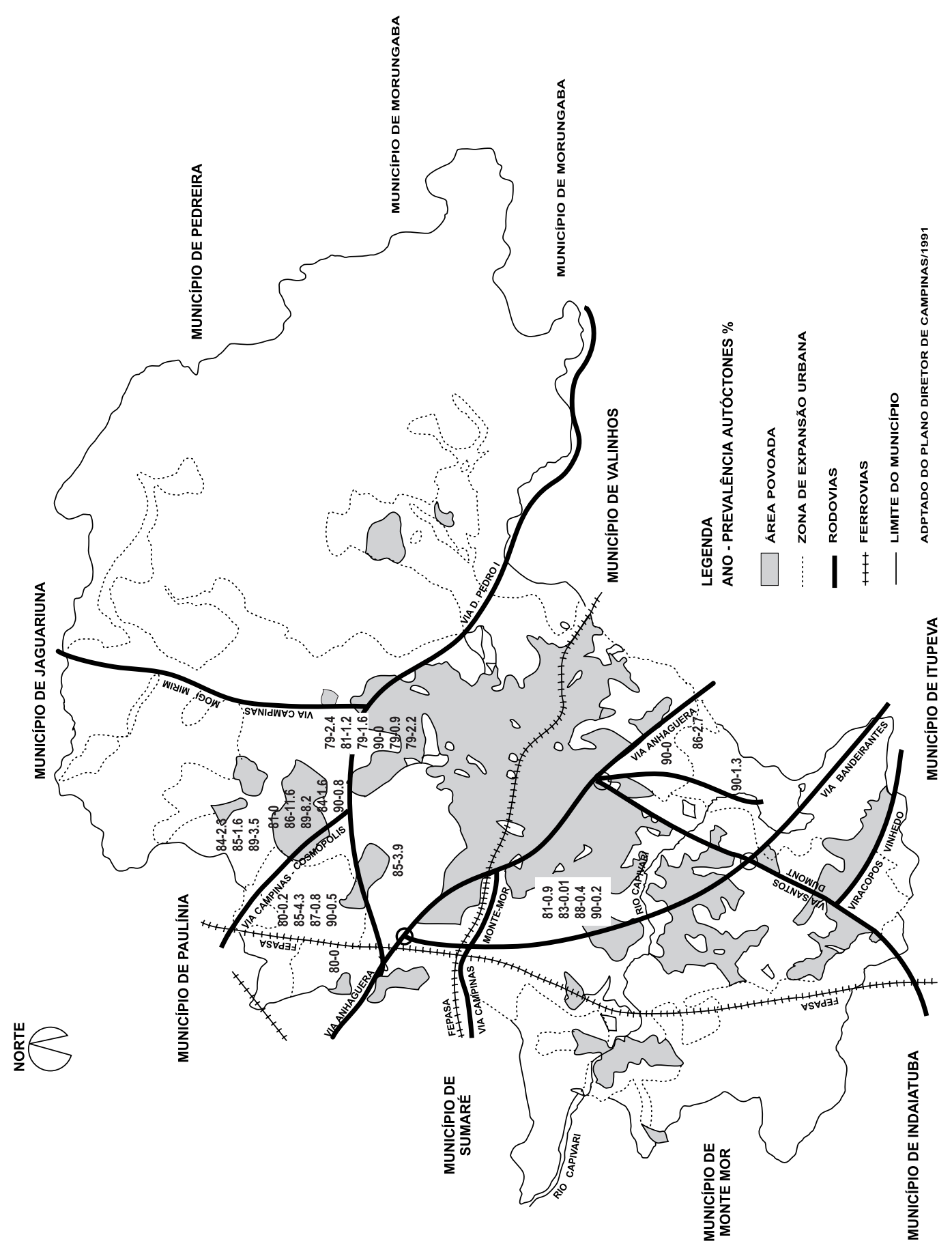


FIGURA 3. Distribuição das Favelas e das Áreas de Transmissão de Esquistossomose, Município de Campinas, 1990

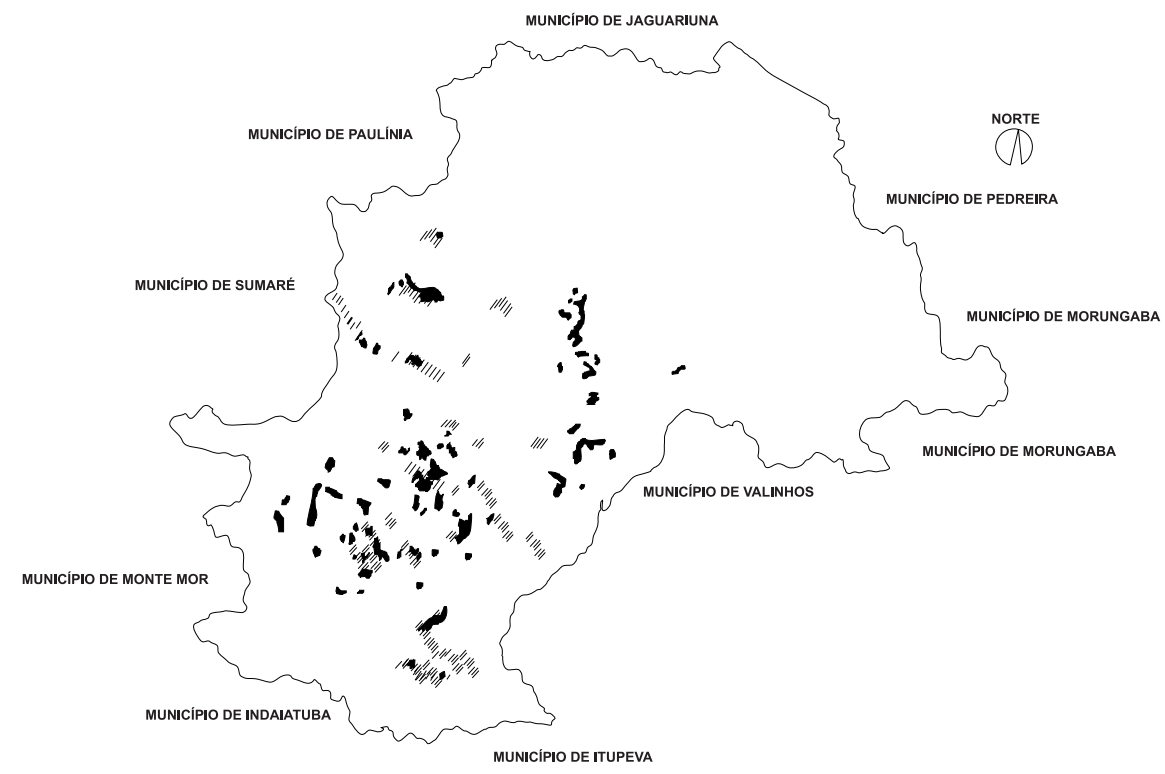

Áreas de transmissão de esquistossomose (adaptado do Plano Diretor do Município de Campinas).

Em relação àqueles casos para os quais se conseguiu determinar o ramo de atividade (Tabela 2), observa-se que predominam entre eles os inseridos no ramo da indústria de transformação, seguidos dos incluídos na prestação de serviços. A agropecuária representa parcela muito pequena. A grande predominância configurou-se na categoria "não-ocupados". Foi importante a percentagem de casos, entre os ocupados, para os quais não se conseguiu determinar o ramo de atividade. Dentro desse mesmo tipo de análise, observou-se que os pacientes com esquistossomose distribuíram-se pelos setores da economia da seguinte maneira: $13,4 \%$ no setor secundário, $10,7 \%$ no terciário e $3,1 \%$ no primário. A comparação com a distribuição da população economicamente ativa do município, de acordo com o recenseamento de 1980 (Prefeitura Municipal de Campinas, 1991), que encontrou 39\% no setor secundário, $56,2 \%$ no terciário e $2,5 \%$ no primário, corrobora a importância do setor secundário na inserção dos pacientes com esquistossomose no mercado de trabalho.

TABELA 2. Casos Autóctones Notificados de Acordo com Ramo de Atividade, Campinas, 1970-1990

\begin{tabular}{lcc}
\hline \hline Ramo de Atividade & Casos & Percentual \\
\hline Administração Pública & 2 & 0,3 \\
Agropecuária & 19 & 3,1 \\
Comércio de Mercadorias & 16 & 2,6 \\
Construção Civil & 7 & 1,1 \\
Indústria de Transformação & 82 & 13,4 \\
Prestação de Serviços & 38 & 6,2 \\
Transporte/Comunicação & 3 & 0,5 \\
Não-ocupados + Desocupados & 344 & 56,4 \\
Informação Insuficiente & 99 & 16,2 \\
\hline Total & 610 & 100 \\
\hline \hline
\end{tabular}


Analisando a evolução das proporções de cada ramo de atividade, por intervalos de cinco anos, no período de 1976 a 1990, observou-se aumento da proporção de indivíduos no ramo da "indústria de transformação" do primeiro para o segundo período (de 5,8\% para $17,1 \%$ ), com discreta queda no último período $(15,7 \%)$, apesar de se manter predominante em relação aos demais ramos. Registrou-se, ainda, grande aumento da proporção de casos no ramo da "prestação de serviços" no último período (de $5,1 \%$ para $11,1 \%$ ).

Observa-se que, de acordo com a Classificação Brasileira de Ocupações, entre os grandes grupos (Tabela 3), predominam os de números 7, 8 e 9, que classificamos "Trabalhadores da produção industrial, operadores de máquinas, condutores de veículos e trabalhadores assemelhados". Vale a pena ainda notar que os grupos com menos casos são os de números 0,1 e 2 . Os grupos 0 e 1 representam as ocupações que exigem maior formação intelectual; são os "Trabalhadores das profissões científicas, técnicas, artísticas e trabalhadores assemelhados". Entre os doentes de esquistossomose englobados nesses grupos, houve predomínio das ocupações técnicas de nível médio, havendo apenas um profissional de nível universitário. O grande grupo 2, "Membros dos poderes legislativo, executivo e judiciário, funcionários públicos superiores, diretores de empresas e trabalhadores assemelhados", também está representado por apenas um componente, classificado como gerente.

$\mathrm{Na}$ Tabela 4 foi feita a divisão dos casos autóctones notificados, após excluir-se a categoria "não-ocupadas". Nela aparecem os desempregados (desocupados), trabalhadores direta- mente ligados à agricultura (grande grupo 6), sobrando, então, os trabalhadores provavelmente urbanos. Nesses, foi feita a divisão entre os serviçais domésticos (grande grupo 5, excluindo policiais), ajudantes e não-qualificados (grupo específico 99), e os que restaram foram colocados sob a denominação "com alguma qualificação". Esses dados, como se pode ver, estão separados em períodos de cinco anos. Observa-se que as ocupações com alguma qualificação aparecem em importante proporção, que aumenta no último intervalo. Vale ainda ressaltar o aumento da proporção de desempregados ao longo do período.

TABELA 3. Casos Autóctones Notificados Agrupados por Ocupação em Grandes Grupos de Acordo com a Classificação Brasileira de Ocupações, Campinas, 1970-1990

\begin{tabular}{lrr}
\hline \hline Grandes Grupos & Casos & $\%$ \\
\hline $\begin{array}{l}\text { Não-ocupados }+ \\
\text { desocupados }\end{array}$ & 344 & 56,3 \\
Sem informação & 36 & 5,9 \\
0 & 11 & 1,8 \\
1 & 2 & 0,3 \\
2 & 1 & 0,2 \\
3 & 27 & 4,4 \\
4 & 14 & 2,3 \\
5 & 23 & 3,8 \\
6 & 13 & 2,1 \\
7 & 41 & 6,7 \\
8 & 55 & 9,0 \\
9 & 43 & 7,0 \\
\hline Total & 610 & 100 \\
\hline \hline
\end{tabular}

TABELA 4. Casos Autóctones Notificados por Agrupamentos de Ocupações, de Acordo com a Classificação Brasileira de Ocupações e por Intervalos de 5 anos, Campinas, 1976-1990

\begin{tabular}{lrrrrrrrr}
\hline \hline & \multicolumn{2}{c}{$76-80$} & \multicolumn{2}{c}{$81-85$} & \multicolumn{2}{c}{$86-90$} & \multicolumn{3}{c}{ Total } \\
\cline { 2 - 9 } Ocupação & $\mathrm{N}^{\mathrm{o}}$ & $\%$ & $\mathrm{~N}^{\mathrm{o}}$ & $\%$ & $\mathrm{~N}^{\mathrm{o}}$ & $\%$ & $\mathrm{~N}^{\mathrm{o}}$ & $\%$ \\
\hline Agricultura & 4 & 9,1 & 4 & 3,7 & 5 & 4,5 & 13 & 5,0 \\
Desempregados & 1 & 2,3 & 5 & 4,7 & 7 & 6,4 & 13 & 5,0 \\
Serviço doméstico & 2 & 4,5 & 6 & 5,6 & 7 & 6,4 & 15 & 5,7 \\
Ajudantes + não-qualificados & 16 & 36,4 & 40 & 37,4 & 20 & 18,2 & 76 & 29,1 \\
Alguma qualificação & 20 & 45,5 & 40 & 37,4 & 63 & 57,3 & 123 & 47,1 \\
Sem informação & 1 & 2,3 & 12 & 11,2 & 8 & 7,3 & 21 & 8,0 \\
\hline Total & 44 & 100 & 107 & 100 & 110 & 100 & 261 & 100 \\
\hline \hline
\end{tabular}




\section{DISCUSSÃO}

Poderiam ser esperados níveis mais elevados de transmissão na região sudoeste, que fica abaixo da rodovia Anhanguera, em relação à região norte, acima dessa rodovia, pois aí se concentra a população pobre da cidade. Isso, no entanto, não foi constatado por meio dos coeficientes de casos autóctones calculados para as duas porções do município. Seria possível pensar que os serviços de saúde situados na região norte fossem mais eficientes na detecção de casos e na notificação; no entanto, as prevalências autóctones dos levantamentos coproscópicos realizados nas duas porções do município mostram valores mais elevados para a região norte. Além disso, há evidências de que, provavelmente, não ocorre subnotificação diferenciada entre as regiões administrativas da cidade (Feliciello, 1985).

As ARs em que reside o maior número de casos autóctones, as ARs 3,7 e 90, estão situadas nos dois eixos de maior expansão da cidade nas 'últimas décadas. É interessante notar que, enquanto a AR 7 (abaixo da rodovia Anhanguera), em virtude dos baixos preços da terra urbana, vem sendo ocupada por famílias de baixa renda, as ARs 3 e 90 (acima da rodovia Anhaguera) se situam em região cuja ocupação tem-se dado por famílias de médio e alto padrão na sua maioria (Prefeitura Municipal de Campinas, 1991; Feliciello, 1985). Indicadores de mortalidade também apresentam padrões bem piores para a AR 7 (SMS \& LAPE, 1991).

Apesar de se ter indicação de transmissão em várias favelas, não parece haver relação direta entre a transmissão da esquistossomose e a presença de favelas.

Analisando, a não-ocorrência de suspeita de transmissão na zona leste do município, poderia ser investigada a existência de características que a diferenciassem das outras zonas em que ocorre. transmissão. O que pode ser levantado é o fato de essa zona não ter sofrido expansão acelerada, como as zonas em que ocorre aparentemente transmissão mais elevada. Trata-se de zona, segundo análise da prefeitura, com potencial de expansão urbana e perspectivas de ocupação por famílias de média e alta renda (Prefeitura Municipal de Campinas, 1991). No entanto, a zona norte, que tem trans- missão importante, é, em relação a esse aspecto, semelhante à zona em questão.

Por fim, um dado a ser lembrado é o relevo dessa região, constituído pelas serras e morros do Planalto Atlântico com altitudes que chegam a ultrapassar 1100 metros. Possui drenagem de grande densidade, diferenciando-se do restante do município, situado na Depressão Periférica (Prefeitura Municipal de Campinas, 1991). De acordo com os dados da Sucen, existem criadouros de B. tenagophila na porção leste do município. Pode-se supor que a drenagem de densidade elevada das coleções hídricas dessa zona estaria impedindo a instalação da transmissão; no entanto, há relatos de transmissão de esquistossomose em coleções de curso corrente (Jordan, 1985). Apesar de terem sido feitas essas observações, para tentar compreender a não-detecção de casos suspeitos de transmissão local nessa porção do município, é necessário estudo mais aprofundado da situação. O município tem mais de $90 \%$ de sua área servida por rede de abastecimento de água tratada e $85 \%$ por rede de esgotos. Como foi relatado, a maioria das áreas de transmissão de esquistossomose é servida de água tratada e de rede coletora de esgoto. Vale observar, ainda, que praticamente todas as coleções hídricas do município estão contaminadas com dejetos humanos, pois apenas $10 \%$ dos efluentes de esgoto recebem tratamento, sendo esse tratamento de tipo preliminar ou, em algumas estações, de tipo primário.

A transmissão da esquistossomose no município de Campinas, pode-se dizer, ocorre em locais com diferentes condições de vida. Mesmo que, devido à imprecisão dos dados disponíveis, não se possa determinar onde exatamente a transmissão se dá com mais intensidade, as duas regiões em que a transmissão parece ser mais intensa apresentam-se diferentes do ponto de vista socioeconômico. Tem-se como variável semelhante nas duas regiões o fato de serem os dois pólos de maior expansão do município nas últimas décadas.

No que diz respeito à ocupação, foi feito esforço para aproveitar as informações disponíveis na ficha epidemiológica pela sua importância para o tipo de análise pretendido. Como 55\% das fichas de casos autóctones notificados eram compostas de estudantes, indivíduos com me- 
nos de 16 anos e mulheres que se ocupam apenas dos afazeres domésticos, as informações relativas à inserção econômica dos indivíduos eram relativas a apenas uma parcela dos casos, pois não se dispunha de informações familiares na ficha epidemiológica. Apesar disso, seguindo esse modelo de análise, conseguiu-se traçar alguns paralelos com as peculiaridades do processo de desenvolvimento econômico e urbanístico do município.

Como foi observado nos resultados, percentagem relativamente elevada dos casos entre os indivíduos ocupados estava inserida na indústria de transformação, superando, mesmo, aquela inserida no ramo de atividade prestação de serviços. Mesmo levando em consideração que, entre a parcela dos indivíduos ocupados, a informação foi insuficiente para agrupar, em algum dos ramos de atividade, percentagem relativamente elevada de casos, a distribuição encontrada surpreendeu. A indicação da qualificação profissional, obtida para maior parcela dos indivíduos, também causou surpresa, mostrando que elevada percentagem dos indivíduos tinha algum grau de qualificação. Pode-se fazer um paralelo do crescimento observado dessa percentagem, ao longo do período estudado, com o aumento da demanda por mão-de-obra qualificada no município devido à instalação de indústrias com tecnologia de ponta no município na última década (Baeninger, 1991).

Existe relação entre o grau de qualificação dos trabalhadores e as condições de vida e saúde (Possas, 1989). Uma estrutura produtiva estável pressupõe elevada proporção de trabalhadores qualificados e, consequientemente, menos mobilidade da força de trabalho e rotatividade da mão-de-obra.

Com esta análise não se quer sugerir que a parcela da população do município de Campinas inserida em algum dos ramos de atividade tenha maior ou menor risco de adquirir esquistossomose. É possível e esperado que, se dados mais consistentes que os obtidos por meio deste estudo se tornassem disponíveis, se evidencie que a parcela da população não inserida na economia urbana produtiva e com condições de vida mais precárias tenha risco mais elevado do que as demais.
$\mathrm{O}$ que os dados aqui analisados permitem afirmar é que os casos de esquistossomose notificados, entre indivíduos ocupados, em elevada proporção, remetem a sujeitos integrados à economia urbana com empregos na indústria. Isso pode indicar que a doença não seja atributo, com maior evidência, da parcela da população alijada da economia urbana. Essa informação, associada às outras obtidas neste estudo e relativas às condições do local de moradia dos pacientes, permite sugerir que a esquistossomose tem distribuição mais heterogênea no município, no que diz respeito à condição socioeconômica, do que poderia ser esperado, com base nos estudos existentes sobre a endemia, em que ela é intimamente relacionada a condições precárias de saneamento básico e de subsistência (Doumenge, 1987).

Pode-se sugerir, também, que a doença tem no município feição tipicamente urbana, pois, além de a transmissão ocorrer nos limites da zona urbana, a maioria das pessoas acometidas está inserida na economia urbana, e poucas na agricultura.

É interessante ainda notar que a proporção de casos de esquistossomose por ramo de atividade ao longo do período de estudo mostra comportamento semelhante à evolução do emprego urbano na grande São Paulo e no interior. O emprego urbano dependeu, entre 1980 e 1990, quase exclusivamente dos novos postos de trabalho gerados pelo setor terciário. As taxas de crescimento do emprego formal na indústria foram, nessa década, bem inferiores às da década anterior (Prefeitura Municipal de Campinas, 1991).

Outra observação digna de nota é a respeito do aumento do percentual de desempregados entre os casos notificados. Registra-se, em Campinas, no final da década de 80, o desemprego aberto como "uma realidade nova" (Prefeitura Municipal de Campinas, 1991) numa economia urbana com elevado percentual de emprego industrial.

\section{CONCLUSÃO}

O dados obtidos sugerem que a esquistossomose autóctone no município de Campinas apresenta distribuição mais heterogênea do que seria de esperar. Apesar de aparentemente não estar presente em uma determinada par- 
cela da população do município - a que reside em bairros com nível de renda situado nas duas faixas mais elevadas, entre as cinco em que foram divididos os bairros de Campinas; a que tem instrução de nível superior; a de altos funcionários, diretores de empresas etc. - a esquistossomose não é atributo com maior evidência da camada da população não inserida na economia moderna. Como foi observado, ela atinge realmente uma proporção dos indivíduos trabalhando em emprego doméstico, em ocupações não-qualificadas, como auxiliares e ajudantes diversos etc. e está presente em alguns bairros sem água e esgoto. No entanto, a maioria mora em bairros com rede de abastecimento de água e esgoto. Na população adulta para a qual foram conseguidas informações sobre a ocupação, observou-se que boa parte dela está inserida na indústria de transformação, e elevada proporção tem algum nível de qualificação para o trabalho. Vale ressaltar a existência de indivíduos, trabalhando em grandes indústrias, como Mercedes Benz, Singer, Clark, Rhodia.

A ocorrência da esquistossomose autóctone nos diferentes estratos da sociedade do município de Campinas reflete antes de mais nada a heterogeneidade estrutural da sociedade brasileira, sendo ela entendida como " a sobreposição de cortes transversais e horizontais, produzindo uma estratificação econômica e social com planos e graus diferentes e assincrônicos de integração" (Tavares \& Serra, 1971: 935). Tal heterogeneidade decorre "das condições históricas (do país) que impediram a integração social através do desenvolvimento econômico, uma vez que este por si só não foi capaz de completá-la" (Possas, 1989: 155). Essa situação estaria vinculada às dificuldades de controle social e político das condições de vida e trabalho (Tavares, 1981).

De acordo com Singer (1987), indivíduos ou famílias inseridos numa atividade produtiva em um centro urbano, por usufruírem de renda, teoricamente, ofereceriam condições ao município de suprir suas demandas de serviços. No caso dos pacientes portadores de esquistossomose autóctone no município de Campinas, a presença dessa parasitose revela que sua qualidade de vida e, principalmente, de lazer não é condizente com sua inserção na econo- mia, apontando essa constatação para o baixo poder de reivindicação dessa população.

\section{RESUMO}

\section{LIMA, V. L. C. A Esquistossomose Urbana e a Heterogeneidade Social e Epidemiológica da População do Município de Campinas, São Paulo, Brasil. Cad. Saúde Públ., Rio de Janeiro, 11 (1): 45-56, jan/mar, 1995.}

Este estudo aborda as relações da esquistossomose com uma das características da urbanização intensa que vem sendo observada nos países de capitalismo tardio, que é a presença de um aglomerado de pessoas, vivendo nas periferias das cidades em precárias condições de vida. Foram estudados 610 casos autóctones notificados da endemia, no município de Campinas (situado a $98 \mathrm{~km}$ da capital), correspondentes ao período de 1970 a 1990 , por meio de suas fichas de notificação epidemiológica, visando avaliar as condições socioeconômicas dos portadores da doença. Constatou-se que a esquistossomose autóctone no município de Campinas apresenta distribuição mais heterogênea do que se poderia esperar com base nos estudos existentes sobre a endemia, em que ela é intimamente relacionada a condições precárias de saneamento básico e subsistência.

Palavras-Chave: Esquistossomose; Urbanização; Geografia Médica; Heterogeneidade Social

\section{REFERÊNCIAS BIBLIOGRÁFICAS}

ALVES, J. C. M., 1983. Schistosomiasis in the Metropolitan Region of São Paulo, Brazil - a Contribution to the Study of its Epidemiology and Control. Tese de Mestrado, Londres: Ross Institute of Tropical Hygiene, London School of Tropical Medicine and Hygiene.

BAENINGER, R.,1991. Espaço e Tempo em Campinas. Tese de Mestrado, Campinas: Instituto de Filosofia e Ciências Humanas, Universidade de Campinas. 
DOLFUSS, O., 1972. O Espaço Geográfico. São Paulo: Difusão Européia do Livro.

DOUMENGE, J. P., 1987. Atlas de la Répartition Mondiale des Schistosomiasis. Genève: OMS/ WHO.

FELICIELLO, D., 1985. Atenção Primária e Política de Saúde. Projeto de Avaliação Permanente em Serviço. Relatório de pesquisa apresentado à FINEP, Campinas. (Mimeo.)

IBGE (Fundação Instituto Brasileiro de Geografia e Estatística), 1983. Censos Demográficos do Estado de São Paulo e do Brasil; 1980: Famílias e Domicílios. Rio de Janeiro: IBGE.

JORDAN, P., 1985. Schistosomiasis. the St Lucia Project. Cambridge: Cambridge University Press.

KNUDSEN, A. B. \& SLOOFF, R., 1992. Problèmes dus aux maladies à transmission vectorielle et urbanisation accélérée: nouvelles approches de Ia lutte antivectorielle. Bulletin de l'Organisation Mondiale de la Santé, 70: 01-06.

KVALSVIG, J. D. \& SCHUTTE, C. H. J., 1986. The role of human water contact patterns in the transmission of Schistosomiasis in an informal settlement near a major industrial area. Annals of Tropical Medicine and Parasitology, 80: 13-26.

LIMA, V. L. C., 1993. A Esquistossomose no Município de Campinas. Tese de Doutorado, Campinas: Faculdade de Ciências Médicas, Universidade Estadual de Campinas.

MT (Ministério do Trabalho), 1982. Classificação Brasileira de Ocupações (CBO), Sistema Nacional de Emprego. Brasília: MT.

MORAES, A. C. R. \& COSTA, W. M., 1987. Geografia Crítica, A Valorização do Espaço. $2^{\mathrm{a}}$ ed., São Paulo: Hucitec.
MOTT, K. E.; DESJEUX, P.; MONACAYO, A.; RANQUE, P. \& RAADT, P., 1990. Parasitic diseases and urban development. Bulletin of the World Health Organization, 68: 691-698.

PREFEITURA MUNICIPAL DE CAMPINAS, 1991. Campinas, Subsídios para Discussão do Plano Diretor. Campinas: IMA.

POSSAS, C., 1989. Epidemiologia e Sociedade, Heterogeneidade Estrutural e Saúde no Brasil. São Paulo, Hucitec.

SEADE (Fundação Sistema Estadual de Análise de Dados), 1983. Análise Demográfica Regional Região de Campinas, o Surgimento de uma Nova Área Metropolitana. São Paulo: Seade.

SES (Secretaria de Estado da Saúde) \& SUCEN (Superintendência de Controle de Endemias), 1982. Relatório da Situação da Esquistossomose no Estado de São Paulo. II Encontro sobre Esquistossomose. São Paulo: SES/Sucen. (Mimeo.)

SMS (Secretaria Municipal de Saúde) \& LAPE (Laboratório de Aplicação em Epidemiologia/ DMPS-FCM-Unicamp), 1991. Informe Trimestral do Projeto de Monitorização dos Óbitos no Município de Campinas. Boletim no 1 - jan a mar. (Mimeo.)

SINGER, P., 1987. Economia Política da Urbanização. 11 $11^{\mathrm{a}}$ ed., São Paulo: Brasiliense.

TAVARES, M. C., 1981. Problemas de Industrialización Avanzada en Capitalismos Tardíos e Periféricos. CECADE.

TAVARES, M. C. \& SERRA, J., 1971. Mas allá del estancamiento: una discusión sobre el estilo del desarrollo reciente. El Trimestre Econó-mico, México, 33: 905-950. 